\title{
Optimum community energy storage for renewable energy and demand load management
}

\author{
David Parra ${ }^{\mathrm{a}}$, Stuart A. Norman ${ }^{\mathrm{b}}$, Gavin S. Walker ${ }^{\mathrm{a}}$, Mark Gillott ${ }^{\mathrm{a}}$ \\ ${ }^{a}$ Energy Technologies Research Institute, Faculty of Engineering, University of Nottingham, \\ University Park, Nottingham NG7 2RD, UK \\ ${ }^{b}$ E.ON UK plc, Newstead Court, Little Oak drive, Annesley, Nottingham NG15 oDR, UK
}

\begin{abstract}
While the management of PV generation is the prime application of residential batteries, they can deliver additional services in order to help systems to become cost-competitive. They can level-out the demand and potentially reduce the cost and emissions of the energy system by reducing demand peaks. In this study, community energy storage (CES) is optimised to perform both PV energy time-shift and demand load shifting (using retail tariffs with varying prices blocks) simultaneously. The optimisation method obtains the techno-economic benefits of CES systems as a function of the size of the community ranging from a single home to a 100-home community in two different scenarios for the United Kingdom: the year 2020 and a hypothetical zero emissions target. It is demonstrated that the levelised cost and levelised value of CES systems reach intermediate values to those achieved when both applications are performed independently. For the optimal performance of a battery system being charged from both local PV plants and the grid, our results suggest that the battery should be sized suitable to ensure it can fully discharge during the peak period.
\end{abstract}

Keywords:

PV technology, energy storage, battery, electricity tariff, decarbonisation

\section{Introduction and literature review}

PV self-consumption by residential batteries has become one of the key business applications for battery energy storage (ES) within the last few years. Although batteries for single dwellings across several countries such as Germany, Australia and California are the niche market at the moment [1, 2, residential batteries for communities, referred to as community energy storage (CES) in this study, are attracting the attention of researchers [3], utility companies [4] and policy makers [5]. CES is being investigated in various research projects,

Email address: David.Parra@unige.ch. Present address:Energy efficiency Group, Institute for Environmental Sciences and Forel Institute, University of Geneva, Switzerland (David Parra) 
many of them involving pilot plants [6] and/or product development and deployment [7. Utility companies are so far one of the key promoters with several programmes worldwide addressing various services such as PV integration and management [4], demand peak shaving $[8$ and other applications for facilitating the proper performance of distribution networks [9].

Roberts and Sandberg argued that CES will be an important asset for managing distributed loads and renewable energy (RE) plants with stochastic generation outputs, facilitating the transition to the "smart grid" [10. Some key advantages of CES systems over single-home ES systems highlighted by the previous literature are: a) enhanced performance of battery systems due to the smoother electricity demand profiles of communities 11; b) relative reduction of the required energy and power ratings of residential batteries for communities in terms of $\mathrm{kWh} /$ home and $\mathrm{kW} /$ home [12; c) potential economies of scale across various components of the battery system (particularly, savings can be made in terms of communications and control equipment) 2]; and d) catalytic effect for implementation of various energy efficiency and RE initiatives in communities following a bottom-up approach [13].

Two important challenges for the further deployment of ES in general and CES in particular are the still high capital expenditure (CAPEX) of most ES technologies (and batteries in particular) and the need for integration several services and/or requirements in order to create attractive economic benefits (i.e. multi-objective use of ES systems) [14, 15]. Various applications could potentially involve different stakeholders such as end users, utility companies and/or distribution system operators (DSOs). However, many previous studies have addressed ES applications independently without discussing the integration of various applications by the same ES system [16, 17. For example, Santos et al. compared four different roles of residential battery storage (PV self-consumption, demand peak shaving, reduction of PV injection into the grid and integration of wind power from the grid) from a techno-economic perspective (required battery capacity, system cost and power exchange with the grid) but these applications were considered as being mutually exclusive [18].

Alternatively, some attempts have made so far to analyse value propositions including several applications. Zucker and Hinchliffe concluded that the optimum ES system is dependent on the grid situation and its final application. Their study considered PV energy time-shift (PVts) in isolation as well as PVts and arbitrage, each application leading to different sizing in terms of hours of discharge and capacity [19]. Sundararagavan et al. included the combination of demand load shifting, frequency regulation and power quality in their analysis, but they only studied the cost of performing these applications assuming some ES properties such as durability and efficiency constant 20. Wade et al. argued that the corresponding economic benefit should be identified in order to prioritise the events which add more value, identifying the stakeholder that can internalise the benefit [21]. From a DSO perspective, a strategy for optimal 
allocation of multiple CES systems including energy arbitrage, peaking power generation, energy loss reduction, system upgrade deferral, emission reduction and VAr support has been proposed [22]. However, the coordination of the ES asset could become a challenge if benefits accrue to different stakeholders. Technical issues such as the lack of engineering standards were also highlighted as key market failures which explain the marginal application of value propositions including several benefits according to a comprehensive report prepared by Sandia for the Department of Energy in USA, [23].

Two previous studies demonstrated for a scenario in 2020 that CES systems managing PV generation (in particular PVts was performed) offer more value than when they manage the community demand (demand load shifting) while the latter allow CES systems to further reduce the levelised cost [11, 12. The work presented here investigates the impact of managing both community PV generation and demand. CES systems performing both PVts and demand load-shifting simultaneously are investigated in order to understand how the combination of applications affect the performance, optimum battery capacities and economic benefits of CES systems. The analysis compares lead-acid (PbA) and lithium-ion (Li-ion) batteries as well as two different retail tariffs for demand load shifting: a time-of-use tariff (Economy 7) and a real-time-pricing tariff including four periods based on the electricity prices from the wholesale market in the United Kingdom (UK). Whether CES performing both applications makes economic sense is investigated as a function of the size of the community (ranging from a single home to a 100-home community) and under two different scenarios: year 2020 and a hypothetical zero carbon scenario. For the 2020 scenario, the battery parameters are based on the targets given by battery manufacturers and government technology agencies [2].

\section{Methodology}

Grid-scale ES systems tend to operate at the distribution level responding to different events on multiple networks with the occurrences of those events given by the network state. CES considered here in this work perform PVts and demand load-shifting on a daily basis. This study follows an end-user perspective and CES systems perform both PVts and demand load shifting without participating in markets such as wholesale electricity and frequency control.

Input data such as community demand, PV generation, battery characteristics as well as the management of CES systems are detailed in this section. The key performance indicators selected for assessing CES systems are introduced together with the optimisation method applied as a function of the size of the community. This methodology has already been presented in two previous publications [11, 12, and, therefore only the key details required to understand the rationale behind it are introduced below. 


\subsection{PV energy time-shift and demand load-shifting}
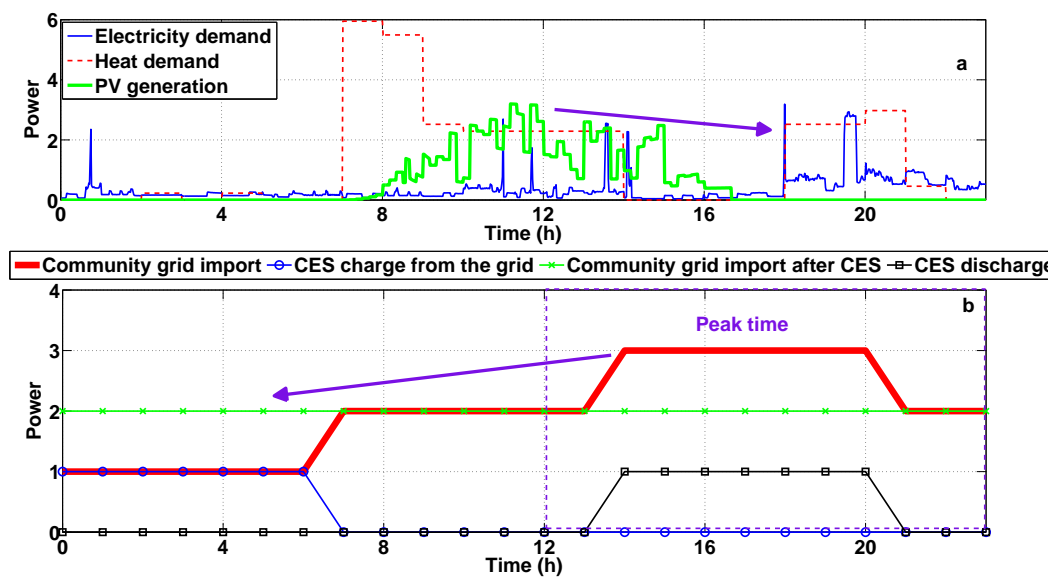

Figure 1: Schematic representation of (a) PV energy time-shift and (b) demand load shifting. No specific units for power are provided in the vertical axis since both graphics are not representative of any particular community.

In this study, we focus on PVts and demand load shifting, both applications being schematically represented in Fig. 1. CES systems can help to increase the amount of PV generation used locally in the community and therefore reduce the impact of weather conditions on the PV self-consumption. PVts consists of storing PV generation when it exceeds the community demand to be used later, typically in the evening. The economic driver for PVts, Rev PVts (£), is the difference between the import price, $P_{i}(£ / \mathrm{kWh})$, and export price, $P_{e x}$ $(£ / \mathrm{kWh})$, as given by Eq. 1 in which $E_{\text {char } P V}(\mathrm{kWh})$ and $E_{\text {dis } P V}(\mathrm{kWh})$ refer to the battery charge and battery discharge respectively with electricity from PV systems. The round trip efficiency, $\eta$, of the battery system should be higher than the ratio between the export and import prices in order for PVts to be economically sensible as shown by Eq. 2 derived from Eq. 1 .

$$
\begin{aligned}
& \operatorname{Rev}_{P V t s}=E_{d i s P V} \times P_{i}-E_{\text {char } P V} \times P_{e x} \\
& \operatorname{Rev}_{P V t s}=E_{\text {char } P V} \times P_{i} \times\left(\eta-\frac{P_{e x}}{P_{i}}\right)
\end{aligned}
$$

Demand load-shifting consists of levelling-out the demand of a community by charging CES systems, $E_{\text {charDLS }}(\mathrm{kWh})$, with off-peak electricity, $P_{i o p}$ $(£ / \mathrm{kWh})$, and discharging electricity to meet the peak demand load later, $E_{\text {disDLS }}(\mathrm{kWh})$, when the price of the electricity is higher, $P_{i p}(£ / \mathrm{kWh})$, as suggested by Eq. 3 used to calculate the related revenue, $\operatorname{Rev}_{D L S}(£)$. From a customer perspective, demand load-shifting is only possible if a retail tariff 
offers different prices depending on the time of day. In this case, the condition for the round trip efficiency given by Eq. 4 is less relaxed since off-peak import prices are typically higher than export prices.

$$
\begin{gathered}
\operatorname{Rev}_{D L S}=E_{d i s D L S} \times P_{i p}-E_{c h a r D L S} \times P_{i o-p} \\
\operatorname{Rev}_{D L S}=E_{c h a r D L S} \times P_{i p} \times\left(\eta-\frac{P_{i o-p}}{P_{i p}}\right)
\end{gathered}
$$

Two different electricity tariffs are included in the analysis. The first one is Economy 7 i.e. a time-of-use tariff with two periods: an off-peak period at night (00:00 to 6:59); and a peak period during daytime hours (7:00 to 23:59). Economy 7 has been used in the UK since the late seventies to shift daily demand to the night period in order to stimulate the use more cost effective based load generation. The second tariff, referred to as "NETA-based", is a real-timepricing tariff with 4 periods based on the prices in the wholesale electricity market in the UK (called NETA market) in 2011. This tariff was created after applying a weighted arithmetic mean of wholesale electricity prices with regard to the total electricity traded on an hourly basis and accounting for other retail price's components such as transport costs, incentives for renewable energies and taxes in the UK. In order to determine the electricity price for the 2020 and the zero carbon scenario (see Table 2), we use an intermediate progression between the average trend for the last 25 years (more conservative increase) and the average trend for the last seven years (more marked increase). While Economy 7 is based on the same electricity prices throughout the year, electricity prices vary throughout the year according to the wholesale electricity prices for the NETA-based tariff. Details about how the NETA-based tariff was built could be found in reference [12. Fig. 2 shows both tariffs in the year 2020 and the zero carbon scenario. Thus, considering both applications, the total battery charge, $E_{\text {char }}(\mathrm{kWh})$, and discharge, $E_{\text {dis }}(\mathrm{kWh})$, are given by Eq. 5 and Eq. 6 respectively:

$$
\begin{gathered}
E_{\text {char }}=E_{\text {char } P V}+E_{\text {char } D L S} \\
E_{\text {dis }}=E_{d i s P V}+E_{\text {dis } D L S}
\end{gathered}
$$

\subsection{Demand data}

Demand data monitored from a total of 102 dwellings which belong to a low carbon community located in the centre of the UK were used for this study 24. The largest community included in this study comprises 100 dwellings. The annual average electricity and heat demands were equal to $3.2 \mathrm{MWh}$ and 12.5 MWh respectively in agreement with the average house in the UK in 2011 [25]. The demand dataset has a temporal resolution of one minute. In all future 


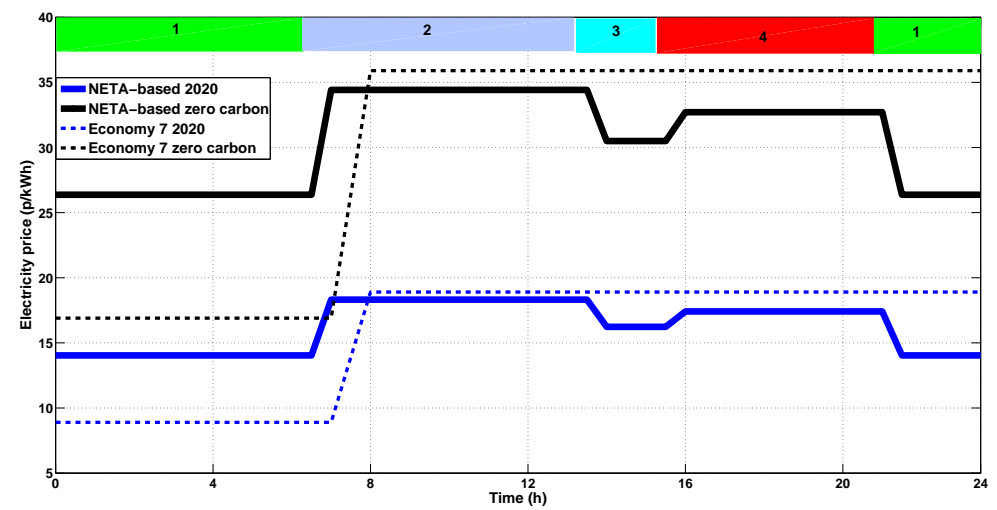

Figure 2: Retail electricity prices for the two tariffs utilised in this study when projected to two different scenarios: 2020 and a hypothetical zero carbon scenario in the UK.

scenarios considered by the UK Government, electric heating becomes more important due to the penetration of heat pumps [26. This study also analyses the impact of meeting the space heating and domestic hot water demands (by using air source heat pumps) on the CES performance, durability and economic benefits. The heat pump model used in this study was validated in a previous study [27] and details of the model can also be found in a previous publication [28. The heat pump percentage ownership for the various communities is explained in Section 2.7.

\section{3. $P V$ generation data}

Together with the demand, solar irradiance was also monitored on-site by the UK Energy Research Centre 24]. We utilise a single diode PV model which was experimentally validated by Villalva et al. 29. The rating of the PV array was assumed to be $3 \mathrm{kWp}$ for all dwellings in close agreement with the average PV installation in the UK in 2013 [30. Moreover, various azimuth angles were considered in order to account for various PV array orientations for a real community (varied between $-50^{\circ}$ and $+50^{\circ}$ according to $10^{\circ}$ degree changes). $\mathrm{PV}$ generation was modelled as a function of the local irradiance and outdoor temperature with a temporal resolution of 1 minute [31. The PV percentage ownership was dependant on the scenario year and is explained in Section 2.7.

\subsection{Battery input data}

Table 1 summarizes the main input data utilised with the battery performance submodel including the maximum charge rating, discharge rating and the depth of discharge depending on the battery technology and current state 
Table 1: Value of the different control parameters implemented for $\mathrm{PbA}$ and Li-ion batteries.

\begin{tabular}{ccc}
\hline \hline Parameter (Unit) & PbA & Li-ion \\
\hline Maximum charge current (A) & $0.2 \cdot \mathrm{C}$ & $3 \cdot \mathrm{C}$ \\
Maximum discharge current (A) & $0.4 \cdot \mathrm{C}$ & $3 \cdot \mathrm{C}$ \\
$\Delta$ SOC & 0.5 & 0.6 \\
Maximum SOC & 0.9 & 0.8 \\
Minimum SOC & 0.4 & 0.2 \\
\hline \hline
\end{tabular}

of art. The battery performance model for both $\mathrm{PbA}$ and Li-ion technologies is explained in SI Section 9.1 .

\subsection{Key performance indicators}

We assess CES systems comprising PbA and Li-ion battery batteries when they perform PVts and demand load shifting simultaneously as a function of the community size and battery capacity through various key performance indicators. Three of these indicators are determined after resolving an annual energy balance for the community. The $P V_{E S}$ is the fraction of the total PV generation, $E_{P V}(\mathrm{kWh})$, which is supplied to the CES system, $E_{\text {char } P V}$, as shown in Eq. 8. The $D_{E S}$ is the fraction of the annual community electrical demand (including the electricity consumption by heat pumps), $E_{d}(\mathrm{kWh})$, met by a CES system $\left(E_{d i s}\right)$ as defined in Eq. 9. The round trip efficiency, $\eta$, is defined according to Eq. 7 as the ratio between the annual electricity discharged by the battery system, $E_{\text {dis }}(\mathrm{kWh})$, and the annual electricity charged into the battery system, $E_{\text {char }}(\mathrm{kWh})$, considering both PV and grid charge at off-peak times. Another indicator used to asses the technical performance of $\mathrm{PbA}$ and $\mathrm{Li}$-ion batteries is the number of equivalent full cycles, $E F C$, given by the Eq. 10 in which $n$ refers to the number of years in operation according to the durability model presented in SI Section 9.1 and $k$ is a generic year. $\mathrm{C}_{n o m}(\mathrm{kWh})$ refers to the nominal battery capacity.

$$
\begin{gathered}
\eta=\frac{E_{d i s}}{E_{c h a r}} \\
P V_{E S}=\frac{E_{P V E S}}{E_{P V}} \\
D_{E S}=\frac{E_{d i s}}{E_{d}} \\
E F C=\frac{\sum_{k=1}^{n} E_{d i s}}{C_{n o m}}
\end{gathered}
$$


The economic assessment follows a life cycle approach by determining the levelised cost of CES, LCOES (£/kWh), levelised value of CES, LVOES $(£ / \mathrm{kWh})$, and internal rate of return, IRR (\%). The levelised cost and levelised value aggregate the different costs and revenues respectively over the total discharge throughout the battery life by calculating their present value (for the year in which the investment is performed) as seen in Eq. 11 and Eq.12 respectively. A discount rate equal to $10 \%$ is utilised here to account for the value of money with time, this value also being used in other previous techno-economic ES evaluations made from a utility company perspective [23, 20]. In Eq. 11. TLC refers to the total levelised cost of a battery system. As shown in Table 2, the total CAPEX of a CES system is comprised of the cost of the storage medium $(£ / \mathrm{kWh})$, inverter cost $(£ / \mathrm{kW})$, balance of plant $(\mathrm{BoP})(£ / \mathrm{kW})$ and maintenance $(£ / \mathrm{kW})$.

$$
\begin{gathered}
L C O E S=\frac{T L C}{\sum_{k=0}^{n} \frac{E_{d i s}}{(1+r)^{k}}} \\
L V O E S=\frac{\sum_{k=1}^{n} \frac{\operatorname{Rev_{DLS}+Rev_{PVts}}}{(1+r)^{k}}}{\sum_{k=0}^{n} \frac{E_{d i s}}{(1+r)^{k}}}
\end{gathered}
$$

Finally, the $I R R$ is a measure of the profitability for the CES investment including all positive and negative cash flows, $C F_{k}(£)$. Since two different services are provided by CES systems, the battery size and CAPEX will be fixed by the application which demands more CES capacity. Likewise, the LVOES will aggregate the benefits created by the two different applications and the application that drives more cycles will have a larger impact in the value.

$$
0=\sum_{k=0}^{n} \frac{C F_{k}}{(1+I R R)^{k}}
$$

\subsection{Optimisation method}

Different to other technologies such as hydrogen and pumped hydro storage, the capacity $(\mathrm{kWh})$ and power $(\mathrm{kW})$ ratings of battery systems are not independent. A battery system is suitable for daily cycling and therefore the charge from the PV arrays and the grid can overlap when PVts and demand load shifting are performed simultaneously. Therefore, integrating these applications by the same battery system requires a strategy which is executed using a forecast of both PV supply and demand.

The optimisation method firstly calculates the maximum CES demand given by the day of the year in which both PVts and demand load shifting requirements are the largest based on some previous monitored data. Then, the largest battery capacity corresponds to the maximum CES demand. In a second step, 


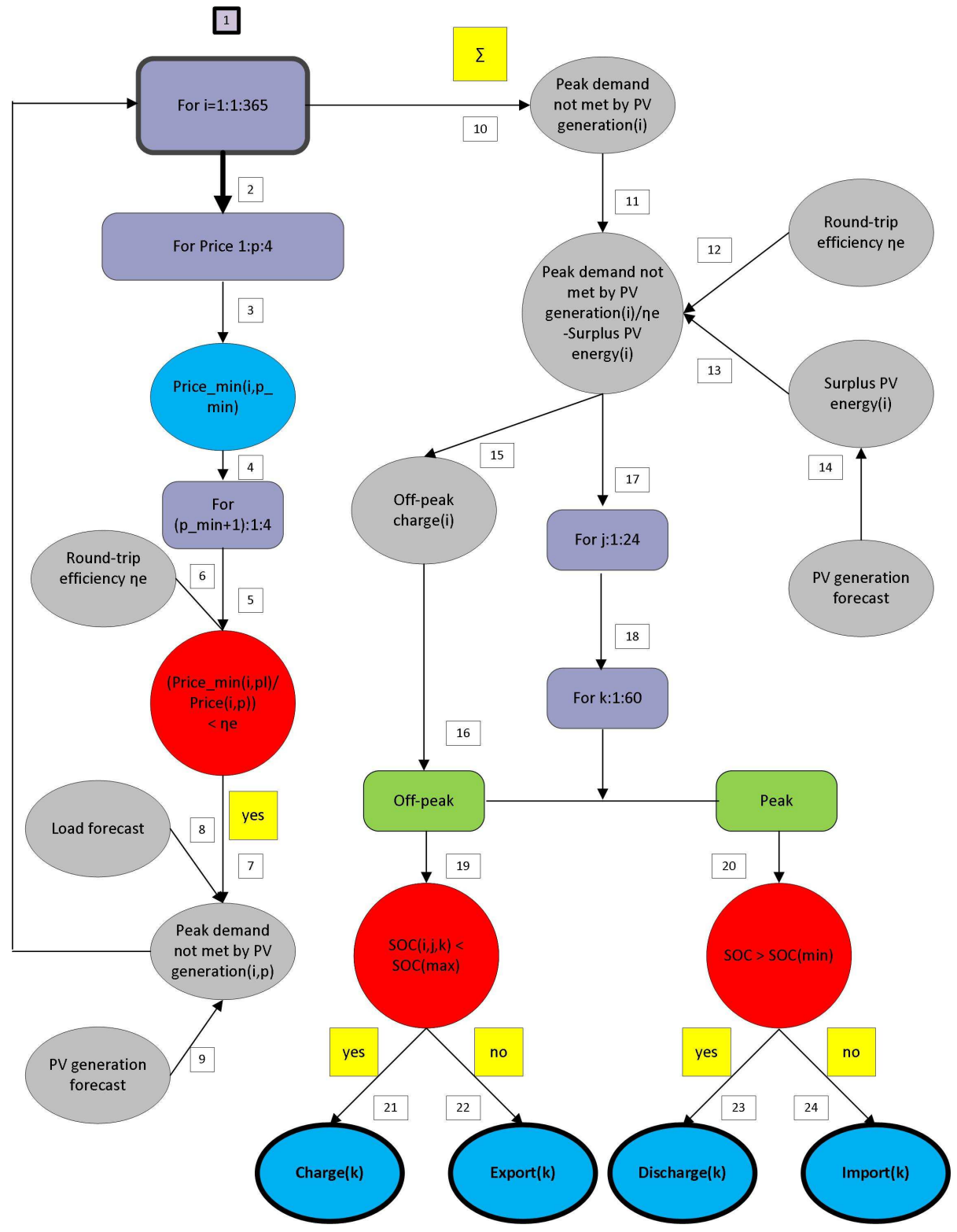

Figure 3: Flow chart representing the algorithm which was utilised to obtain the performance of a battery system when performing PVts and demand load shifting with the NETA-based tariff using 1 minute (loop variable $\mathrm{k}$ ) data for every day (loop variable i) of the year. The flowchart sequence follows the number sequence in the boxes. The sum symbol represents the aggregation of results to obtain daily daily values from hourly data. The index p represents the four periods of the NETA-based tariff. 
the performance and economic benefits of CES systems are determined for every day of the year for a total of 10 battery capacities. The minimum battery capacity as well as the capacity resolution are equal to one tenth of the maximum. The ten battery capacities for both retails tariffs and each community size are shown in Fig. 14 and Fig. 15 of the SI Section 9.3 for the year 2020 and the hypothetical zero carbon scenario respectively. Finally, performance and economic results are aggregated throughout the year and compared in order to select the optimum battery capacity.

The algorithm to determine the maximum battery capacity for CES systems performing both PVts and demand load shifting simultaneously and only demand load shifting are schematically represented in Fig. 11 and Fig. 12 respectively in SI Section 9.2. The main difference between them lies in the calculation of the peak demand load which the battery should meet the day after. When PVts is also considered, the community demand load, PV generation and round trip efficiency of the CES system are used as input data to calculate firstly the fraction of the demand load met by the PV generation and then, the surplus available PV energy which reduced the demand load shifting requirements. The fraction of the peak demand load directly met by PV generation is then subtracted from the total peak demand load to be shifted when only demand load shifting is performed. Finally, the community energy balance as well as the battery charge and discharge are aggregated throughout the year in order to determine various key performance indicators and select the optimum CES system as shown in Fig. 3. Similar algorithms for PVts and demand loadshifting individually can be found in references [11, 12].

While the algorithm which determines the maximum battery capacity uses monitored PV generation and demand data, the calculation of the optimum battery capacity should be based on day-ahead forecast of both PV generation and demand load in order to simulate real performance conditions. In a real application, the off-peak charge of the battery should be estimated in advance in order to allocate the PV charging afterward therefore there is uncertainty since both the daily PV generation and demand profiles are unknown. The off-grid charge calculation is also affected by the battery round trip efficiency as shown in Fig. 3. In this study, perfect forecast was used to quantify the techno-economic performance regardless of any specific forecast methodology. This identifies the maximum possible benefits/value which could be provided by the battery system. Moreover, electricity charged from the PV plants was prioritized over electricity charged from the grid because it is generated on-site by the end users' PV plants and it has more value (the cost of importing electricity from the grid is higher than the value assigned to the PV electricity export). Finally, the electricity charged from the PV arrays was only discharged at peak times. 
Table 2: Summary of the input data selected for the scenarios, including the electricity price, PV generation, demand and battery properties.

\begin{tabular}{|c|c|c|}
\hline Parameter & 2020 & Zero carbon \\
\hline Electricity price $(\mathrm{p} / \mathrm{kWh})^{a}$ & 16.3 & 31.0 \\
\hline Export feed-in tariff $(\mathrm{p} / \mathrm{kWh})^{b}$ & & 3.2 \\
\hline PV penetration $(\%)^{c}$ & 7.6 & 57.0 \\
\hline HP penetration ${ }^{c}$ & 14 & 100 \\
\hline Electricity demand $(\mathrm{MWh} / \text { year })^{c}$ & up to 2.9 & up to 2.4 \\
\hline Space heating demand $(\mathrm{MWh} / \text { year })^{c}$ & up to 10.3 & up to 6.1 \\
\hline DHW demand (MWh/year) ${ }^{c}$ & Current & Current \\
\hline Inverter cost reduction $(\%)^{d}$ & -25 & -30 \\
\hline $\mathrm{BoP} \operatorname{cost}(£ / \mathrm{kW})^{e}$ & 50 & 45 \\
\hline Maintenance cost $(£ / \mathrm{kW})^{e}$ & 6.5 & 6.5 \\
\hline Maximum cycle life $(\mathrm{EFC})^{f}$ & 1250 & 1500 \\
\hline $\mathrm{Z}(\% / \mathrm{EFC})^{g}$ & 0.024 & 0.02 \\
\hline Calendar losses $(\% / \text { month })^{h}$ & 0.15 & 0.12 \\
\hline Storage medium cost $(£ / \mathrm{kWh})^{i}$ & 150 & 65 \\
\hline Maximum cycle life $(\mathrm{EFC})^{f}$ & 3000 & 3600 \\
\hline $\mathrm{Z}(\% / \mathrm{EFC})^{g}$ & 0.01 & 0.0083 \\
\hline Calendar losses $(\% / \text { month })^{h}$ & 0.09 & 0.08 \\
\hline Storage medium cost $(£ / \mathrm{kWh})^{i}$ & 310 & 160 \\
\hline
\end{tabular}

${ }^{a}$ The price of the utilities was estimated using an average trend of those followed in the last 25 years and last seven years 32 .

${ }^{b}$ export bonus in 2012 33.

$c$ Based on estimations from the UK Government [26]. The annual space heating and DHW demand of the average household was $16.8 \mathrm{MWh}$ in 2006 and the annual electricity consumption was 3.0 MWh 34.

${ }^{d}$ Cost reduction according to the one in the last 15 years 35 over current cost based on data from SMA Solar Technology AG e.g. $£ 1100$ for a $3 \mathrm{~kW}$ single phase inverter.

$e$ Based on published data from the Department of Energy (DOE) 36].

${ }^{f}$ Confirmed with manufacturers including Solom and Hitachi.

$g$ Based on linear capacity reduction considering the assumed $\Delta$ SOC.

${ }^{h}$ Monthly battery capacity percentage reduction.

${ }^{i}$ From available literature [37, 38, 39]. 


\subsection{Scenarios}

It has been previously reported in the literature that the value of ES increases with the penetration of RE technologies [40, 39. We therefore analyse CES in two different scenarios based on PV and heat pump penetrations but also the evolution of capital cost of batteries, electricity prices and community demand: 2020 and a hypothetical zero carbon scenario. In order to model them, cost targets from battery manufacturers [41] as well as the decarbonisation objectives of the UK Government were utilised [26]. In particular, the 2020 scenario is based on mid-term objectives while deep decarbonisation with battery technologies reaching a high level of maturity were assumed for the "zero carbon" scenario. Table 2 summarizes all the input data selected for the two different reference years. This study does not include a sensitivity analysis but the impact of various input parameters on the techno-economic benefits of residential batteries was already analysed for single homes [42, 43] and communities [28] respectively.

The PV and heat pump penetration ownership refer to the proportion of homes in a community with a PV array and a heat pump, respectively. CES systems are prioritised for homes with a PV array up to a certain limit set by the PV penetration. For example, as the size of the community increases, the community PV percentage changes from $100 \%$ for a single home to $57 \%$ (equal to the PV penetration given in Table 2 for a 100-home community in the zero carbon scenario. Given the still low PV penetration in the UK by 2020 (7.6\%), we only simulate communities up to 50 dwellings in this scenario (with a PV percentage equal to $15.2 \%$ ).

The heat pumps were randomly introduced across the homes of the community based on the UK penetration given in Table 2. Total electrification of the heat sector was assumed for the zero carbon scenario i.e. each house has a heat pump. For a more comprehensive explanation of the PV penetration and heat pump penetration, the readers are directed to references: [11, 12.

\section{Performance results}

Results for $\mathrm{PbA}$ batteries are presented here to analyse the impact of the combination of applications on both the battery performance and community energy balance. Figure 4 shows the performance results of $\mathrm{PbA}$ batteries as a function of the battery capacity and the community size determined when projected to the year 2020 with the NETA-based tariff. Which application is predominant for each battery capacity and community size is reflected on the various values and patterns. The community $\mathrm{PV}$ percentage is higher than $76 \%$ up to the 10-home community and as a consequence, the $E F C$, round trip efficiency and $D_{E S}$ were more affected by the energy charged from surplus PV generation within the community. The $P V_{E S}$ reached a low (i.e. the PV electricity export is relatively high) when the PV penetration was higher than $76 \%$ because PV electricity was only discharged at peak times. The community PV 

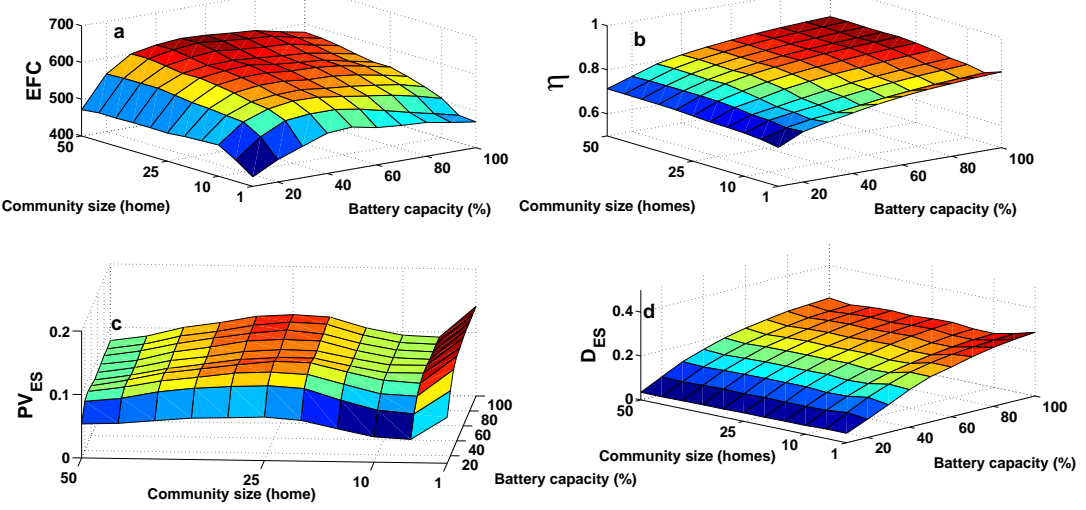

Figure 4: Performance results of $\mathrm{PbA}$ batteries performing PVts and demand load-shifting with the NETA tariff in 2020 as a function of the size of the community and the battery capacity: (a) equivalent full cycles, (b) round trip efficiency, (c) $P V_{E S}$ and (d) $D_{E S}$. The battery capacity is given as a percentage of the maximum ES demand.

percentage was lower than $40 \%$ for the communities with more than 20 homes. In these circumstances, most electricity charge comes from the grid at off-peak periods and this increased the number of equivalent full cycles up to $616 \mathrm{EFC}$ for a 50 home community.
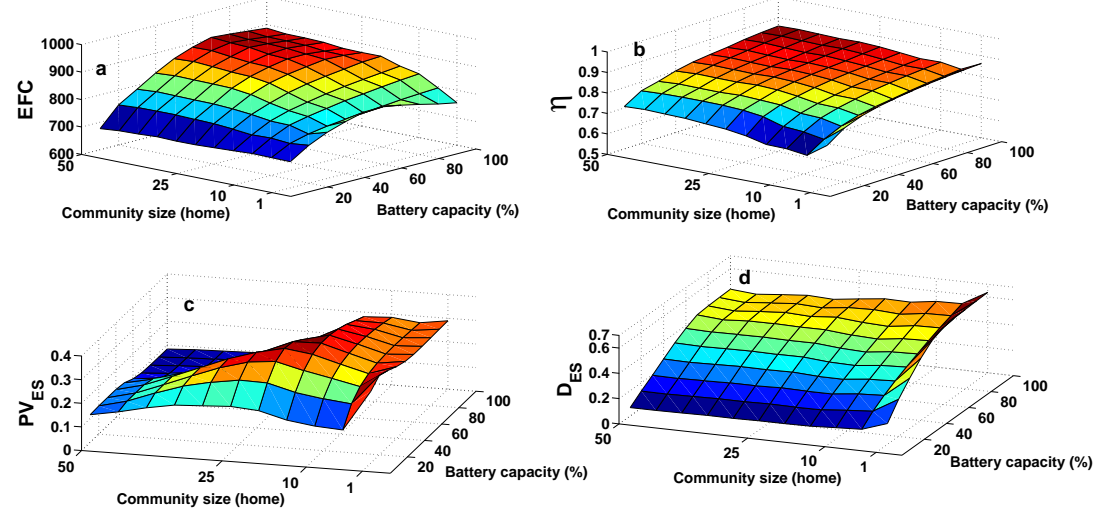

Figure 5: Performance results of $\mathrm{PbA}$ batteries performing PVts and demand load-shifting with Economy 7 in 2020 as a function of the size of the community and the battery capacity: (a) equivalent full cycles, (b) round trip efficiency, (c) $P V_{E S}$ and (d) $D_{E S}$. The battery capacity is given as a percentage of the maximum ES demand. 
Table 3: Performance parameters optimised for PbA and Li-ion batteries for PVts and demand load shifting when projected to 2020 and the zero carbon year. The size of the community (dwellings) and the capacity of the battery $(\mathrm{kWh})$ which achieved the optimum values is shown in brackets.

\begin{tabular}{ccccccc}
\hline \hline Year & Battery & Tariff & $\boldsymbol{E F C}$ & $\eta$ & $\boldsymbol{P} \boldsymbol{V}_{E S}$ & $\mathbf{D}_{E S}$ \\
\hline \multirow{2}{*}{$\mathbf{2}$ PbA } & NETA-based & $616(50,440)$ & $0.87(45,598)$ & $0.14(1,49)$ & $0.29(1,49)$ \\
& \multirow{2}{*}{ Li-ion } & Eco7 & $905.3(50,564)$ & $0.88(100,1073)$ & $0.34(15,101)$ & $0.64(1,7)$ \\
& & NETA-based & $1442(20,29)$ & $0.89(45,536)$ & $0.14(1,48)$ & $0.41(1,48)$ \\
& \multirow{2}{*}{ Eco7 } & $1836(10,261)$ & $0.89(1,88)$ & $0.33(5,81)$ & $0.89(1,88)$ \\
\hline \multirow{2}{*}{$\begin{array}{c}\text { Zero } \\
\text { carbon }\end{array}$} & \multirow{2}{*}{ Li-ion } & NETA-based & $705(100,974)$ & $0.87(90,2106)$ & $0.13(1,18)$ & $0.30(1,38)$ \\
& NEco7 & $1005(100,866)$ & $0.88(75,1557)$ & $0.31(1,11.8)$ & $0.67(1,50)$ \\
& & Eco7 & $1639(100,208)$ & $0.89(70,1506)$ & $0.12(1,16)$ & $0.31(1,36)$ \\
\hline \hline
\end{tabular}

The fraction of the community demand met by the CES operation is greater when PVts is combined with demand load shifting with Economy 7 as shown in Fig. 5. The $P V_{E S}$ is much higher due to the longer peak period of Economy 7 since batteries are sized according to the demand at peak time (after subtracting the peak demand load fraction which is met directly by local PV generation). The $P V_{E S}$ has a much flatter profile for any community size as a consequence it reached its maximum (0.35) for medium battery capacities $(105 \mathrm{kWh}$ battery in the 20-home community) and then it slightly declined. Same conclusions to those extracted from $\mathrm{PbA}$ results apply for Li-ion batteries in terms of the impact of the size of the community and the battery capacity when considering the higher round trip efficiency and discharge ratings of Li-ion chemistry discussed in previous sections.

\section{Economic results}

Figure 6 shows the optimum battery capacity which minimised the levelised cost of performing PVts, demand load-shifting and the combination of them with the NETA-based tariff and Economy 7 for PbA technology in 2020 and the zero carbon year. The optimum capacity which minimises the levelised cost of meeting the demand load with PVts and the NETA-based tariff is $95 \%$ the capacity when only considering demand load-shifting in the zero carbon year and a PV penetration of $57 \%$. This percentage reduces to $75 \%$ for Economy 7 . This suggests that results from demand load-shifting should be used as a guideline to analyse the results when these applications are combined. The impact of adding PV management to demand load management for CES operation in terms of cost, profitability and revenue is discussed next.

Fig. 7 compares the optimum LCOES, LVOES and the IRR for PbA technology when performing PVts, demand load-shifting and both application simultaneously with the NETA-based tariff and Economy 7 respectively. For any 


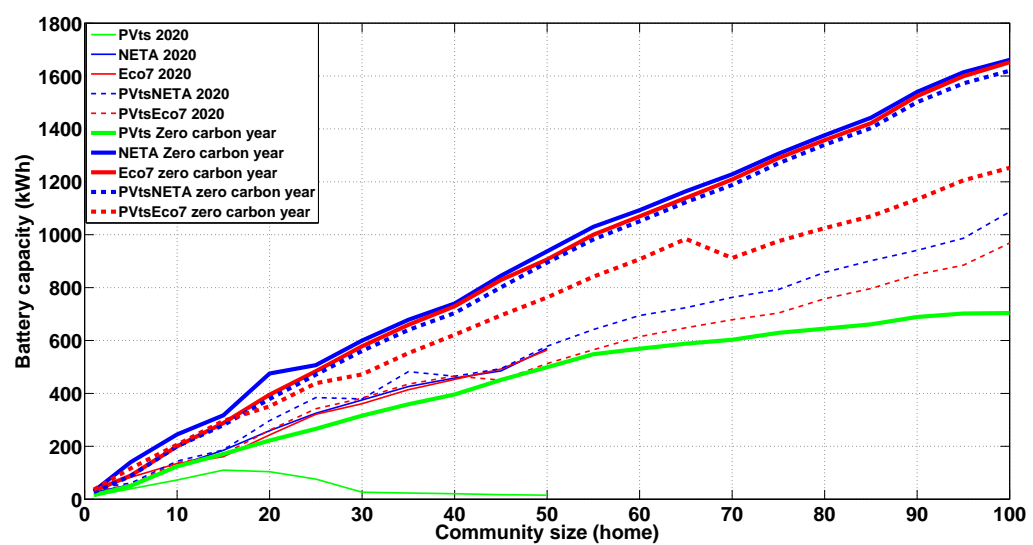

Figure 6: Optimum PbA battery capacity which minimised the levelised cost ( $L C O E S$ ) associated with PVts, demand load-shifting and both applications combined with the NETA-based tariff and Economy 7 as a function of the size of the community in 2020 and the zero carbon year.

community, the optimum battery capacity performing both applications simultaneously decreases regarding the case in which only demand load-shifting is performed but the energy managed by the battery reduces more due to the PV energy supplied directly to the demand load. For example, while a $185 \mathrm{kWh}$ battery performing PVts and demand load-shifting simultaneously minimises the LCOES by annually supplying $9763 \mathrm{kWh}$ in a 15 -home community, a $186 \mathrm{kWh}$ battery performing only demand load-shifting is able to annually shift 12866 $\mathrm{kWh}$ in the same community. As a result, the combined management of PV generation and demand load reduces the $E F C$ from $635 \mathrm{EFC}$ to $542 \mathrm{EFC}$ in this case. Secondly, CES systems only discharge at peak times and this reduces the overall charge of the battery from the PV plants and the grid. As a result, the LCOES increases from $0.35 £ / \mathrm{kWh}$ to $0.42 £ / \mathrm{kWh}$ when the battery performs $\mathrm{PVts}$ in addition to demand load-shifting.

However, the consideration of the PV management increases the profitability of CES systems and the value associated with the discharge. Using local PV generation is more attractive from a financial point of view than shifting demand load with the NETA-based tariff. For a 5-home community with a community PV percentage ownership of $100 \%$, the IRR and the LVOES increase up to $-16.2 \%$ and $0.16 £ / \mathrm{kWh}$ respectively, which means a $19 \%$ and $167 \%$ increase regarding only demand load-shifting (-20.0\% and $0.06 £ / \mathrm{kWh}$ respectively). The remarkable increase in the LVOES is related to the fact that PV energy is only discharged at peak times. This effect is stronger for community PV percentage ownership higher than $75 \%$. 

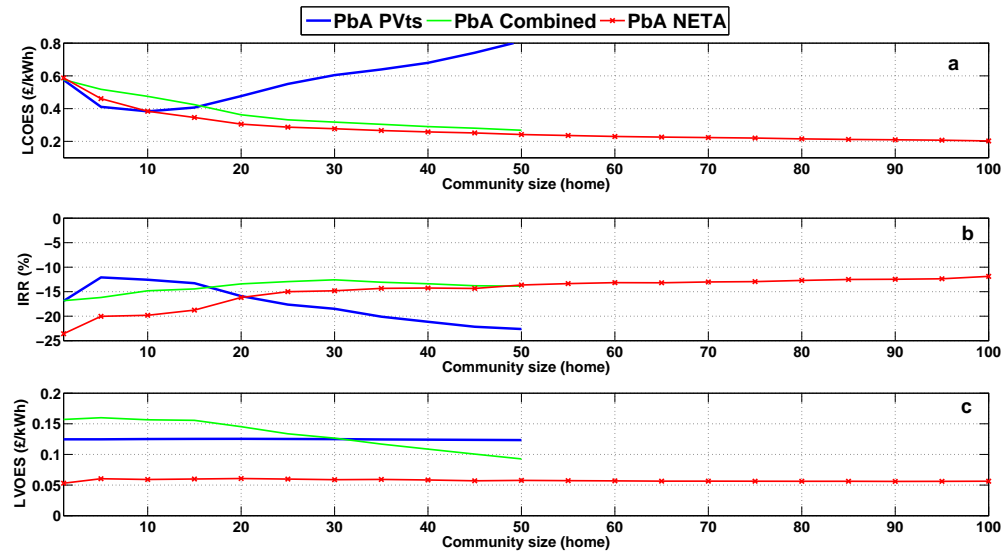

Figure 7: Optimised (a) LCOES, (b) IRR and (c) LVOES as a function of the size of the community for $\mathrm{PbA}$ technology depending on the application developed when considering the NETA-based tariff for demand load-shifting in 2020.
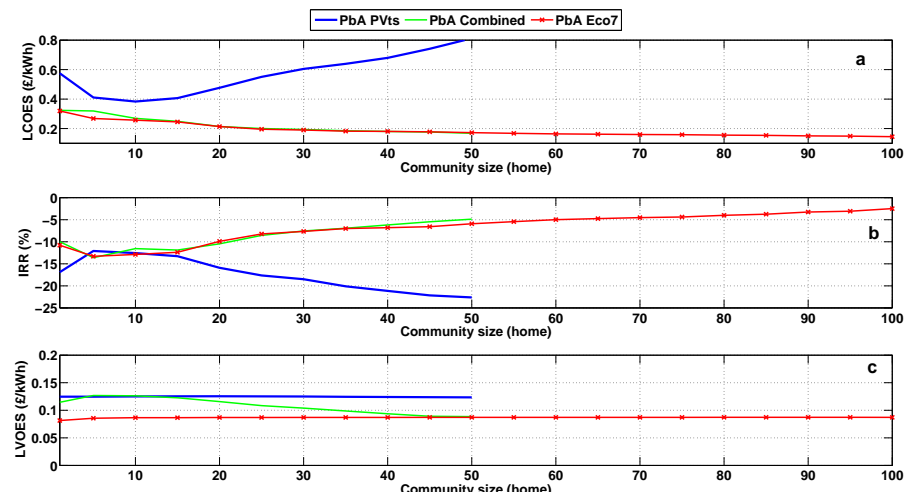

Figure 8: (a) Optimised LCOES, (b) IRR and (c) LVOES for PbA technology as a function of the size of the community depending on the application when considering Economy 7 for demand load-shifting in 2020 .

PVts introduces the same effects when incorporated with demand loadshifting with Economy 7 as shown in Fig. 8. However, the larger annual discharge achieved with this tariff buffers the impact of adding PVts. Additionally, charging from the grid is not as limited as it is with the NETA-based tariff due to the much longer peak period of Economy 7. As a consequence, the LCOES just slightly increases because the electricity generated from the PV plants counterbalanced the reduction of the shifted demand load. In the case of a 5-home community (100\% of PV percentage), the LCOES increases 
by $19 \%$ (from $0.27 £ / \mathrm{kWh}$ to $0.32 £ / \mathrm{kWh}$ ). Again, PVts markedly increases the value associated with the battery discharge to $0.128 £ / \mathrm{kWh}$ for a 5 -home community (it was equal to $0.086 £ / \mathrm{kWh}$ with Economy 7 ). Also, the LVOES is higher than when only PVts is considered $(0.125 £ / \mathrm{kWh})$ for community PV percentages higher than $75 \%$ since the electricity charged from the PV plants is discharged only at peak time. The consideration of PVts does not modify the profitability of the project markedly and the IRR only increased from $-12.9 \%$ to $-11.6 \%(10 \%)$ for a 10 -home community due to the lower impact of the electricity charged from the PV plants on an annual basis.
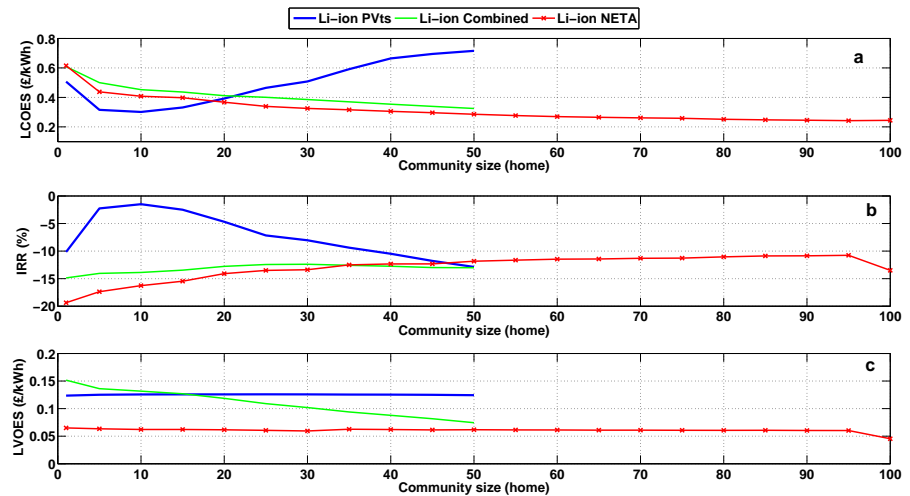

Figure 9: (a) LCOES, (b) IRR and (c) LVOES optimised for Li-ion technology as a function of the size of the community depending on the application when considering the NETA-based tariff for demand load-shifting in 2020.

Fig. 9 and Fig. 10 show the results for Li-ion batteries when PVts is combined with the NETA-based tariff and Economy 7 respectively. The combination of applications make the maximum LVOES obtained by $\mathrm{PbA}$ and Li-ion batteries different. The LVOES is derived from the revenues given by Eq. 2 and Eq. 4 . i.e. it is proportional to the round trip efficiency. Previous studies demonstrated that the maximum LVOES for both PVts and demand load shifting is achieved by the battery with the largest capacity since it performed more efficiently, the maximum round trip efficiency of $\mathrm{PbA}$ and Li-ion technologies being very similar in these circumstances (since the battery its oversize) [11, 12]. When both applications are combined, the maximum LVOES is given by the batteries with the smallest capacity in which the fraction of energy charged from the PV plants is higher regardless of the community size. While Li-ion batteries offer high round trip efficiency for low capacities for any community size 11, $\mathrm{PbA}$ technology requires larger capacities to achieve similar values. This is the reason why the maximum LVOES achieved by Li-ion batteries when being charged from the PV plants and the grid using Economy $7(0.141 £ / \mathrm{kWh})$ is higher than the value achieved by $\mathrm{PbA}$ batteries $(0.126 £ / \mathrm{kWh})$. In the case of 
Table 4: Economic parameters optimised for PbA and Li-ion batteries using PVts and demand load shifting when projected to the year 2020 and a zero carbon year. The size of the community and the capacity of the battery $(\mathrm{kWh})$ which achieved the optimum values is shown in brackets.

\begin{tabular}{cccccc}
\hline \hline Year & technology & Tariff & LCOES (£/kWh) & IRR(\%) & LVOES(£/kWh) \\
& PbA & NETA-based & $0.27(50,570)$ & $-12.6(30,463)$ & $0.16(5,13)$ \\
& & Eco7 & $0.17(50,564)$ & $-5.0(50,564)$ & $0.13(5,20)$ \\
2020 & \multirow{2}{*}{ Li-ion } & NETA-based & $0.33(50,316)$ & $-12.4(30,417)$ & $0.15(1,5)$ \\
& & Eco7 & $0.20(50,358)$ & $-1.5(10,159)$ & $0.14(5,11)$ \\
\hline \multirow{2}{*}{ PbA } & NETA-based & $0.10(100,1620)$ & $24.2(60,631)$ & $0.33(1,4)$ \\
Zero & \multirow{2}{*}{ Li-ion } & Eco7 & $0.06(100,1253)$ & $64.2(100,674)$ & $0.27(25,68)$ \\
carbon & & NETA-based & $0.14(100,821)$ & $16.0(70,304)$ & $0.31(1,3)$ \\
\hline \hline
\end{tabular}

the NETA-based tariff, the round trip efficiency played the same role but the off-peak and peak prices were variable on a daily basis. Given its (relatively) modest round trip efficiency, $\mathrm{PbA}$ batteries only discharge when the peak prices are much higher than the off-peak prices and this impacts on the revenue obtained by PVts i.e. it increases the LVOES up to $0.16 £ / \mathrm{kWh}$. The maximum LVOES of Li-ion technology is $0.136 £ / \mathrm{kWh}$.
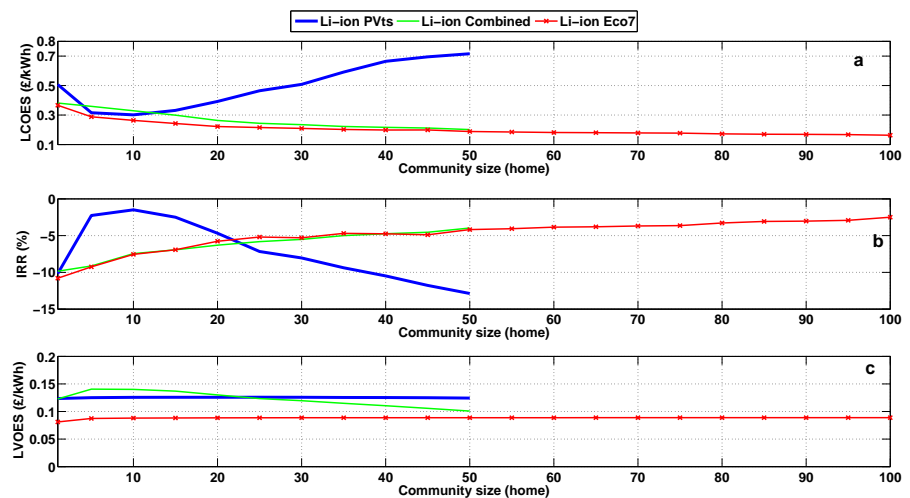

Figure 10: (a) LCOES, (b) IRR and (c) LVOES optimised for Li-ion technology as a function of the size of the community depending on the application when considering Economy 7 for demand load-shifting in 2020 .

\section{Discussion}

When CES systems perform PVts and demand load-shifting simultaneously, the performance is fixed by the combined effects introduced by both applications. Which application is more relevant depends on the management system 
and the CES size. The management system determines which application has priority for charging the CES system (PVts in this work) and whether PV electricity is only discharged at peak periods (this was assumed in this work). Then, increasing the size of the CES system intensifies the importance of the application which does not have priority counterbalancing the results. The decision whether to discharge PV electricity only at peak time or extend it to off-peak time could be further investigated in future work. It is suggested that this is done on a daily basis depending on the amount of PV charge, battery size, peak time duration, off-peak and peak prices.

The combination of PVts and demand load-shifting introduces a dilemma related to the different nature of the electricity which is managed by a CES system. When only PV electricity is managed, electricity charged from the PV plants is discharged whenever the demand is higher than the PV generation (assuming enough battery charge). Likewise, electricity which is charged from the grid when the price of the electricity is low is discharged at peak times when only demand load-shifting is performed. Nevertheless, when electricity is charged from both PV plants and the grid simultaneously, the fraction charged from PV plants can also be discharged during the valley period while the fraction charged from the grid should strictly be discharged at peak time. However, the difference between the valley and the peak price may make the annual revenue higher when the PV electricity is only discharged at peak time. Therefore, additional research is needed to evaluate the optimal charging process from both PV plants and the grid considering various criteria such as community impact, ageing and economic profitability and environmental impact, in particular in countries with high carbon intensity. Moreover, more realistic forecast strategies should be included in future studies in order to determine the profitability without perfect day-ahead information.

The methodology used input data from the UK for modeling PV generation, demand and heat generation. These input data should be updated when possible for 2020 and the hypothetical zero carbon year. Likewise, the methodology could be given a wider scope by using input data from different countries or for other distributed generation resources such as wind electricity. From another perspective, this methodology could be implemented for local communities or developments in which there is less uncertainty in the input data. This could be very useful for utility companies, energy service companies and consultancies which want to design, build and integrate optimal CES systems for a community or development with specific RE generation and demand load requirements. So far, the lack of infrastructure and incentives to install CES systems together with some regulatory barriers related to the supply of electricity among consumers made individual homes the first option for the deployment of residential batteries, Germany being a good example. This work gives conclusive evidences for alternative sizing. 


\section{Conclusions}

The performance, economic benefits and optimum battery capacities for CES systems performing PVts and demand load-shifting simultaneously were quantified as a function of the size of the community. Economy 7 is an attractive tariff for charging batteries from both PV plants and the grid given the long peak period which allows a high fraction of the demand to be shifted while integrating the surplus PV electricity available. Our results suggest that discharging only at peak time is not the optimum solution when the peak period is not long enough to integrate the discharges associated with PVts and demand load-shifting $(<8 \mathrm{~h})$. In order to illustrate this conclusion, the LCOES of the optimum $\mathrm{PbA}$ battery performing in a 5-home community increases from 0.35 $£ / \mathrm{kWh}$ to $0.42 £ / \mathrm{kWh}(20 \%)$ when PVts is added to demand load-shifting with the NETA-based tariff.

PVts increases the LVOES of CES while demand load-shifting has the potential to reduce the LCOES as demonstrated with Economy 7. PVts and demand load-shifting are competing applications for battery technology. PVts reduces the amount of community grid import which is shifted because a fraction of it is directly met by the PV generation, ranging from $26 \%$ for a single home with a HP to $30 \%$ for communities with more than 30 homes. We conclude that Li-ion is the the best technology for communities with large fraction of PV generation, in particular for values of PV percentage ownership higher than $50 \%$ while $\mathrm{PbA}$ should be the technology choice when demand load-shifting is the prime application. In order to manage both local PV generation and demand load with an optimal balance of performance and profitability, utility companies and battery suppliers should consider Li-ion battery capacities of $230 \mathrm{kWh}, 360 \mathrm{kWh}$ and $670 \mathrm{kWh}$ for a 20 -home, 50 -home and 100-home communities respectively, these values being $132 \mathrm{kWh}, 320 \mathrm{kWh}$ and $600 \mathrm{kWh}$ for Li-ion batteries.

\section{Acronyms, nomenclature and list of symbols}

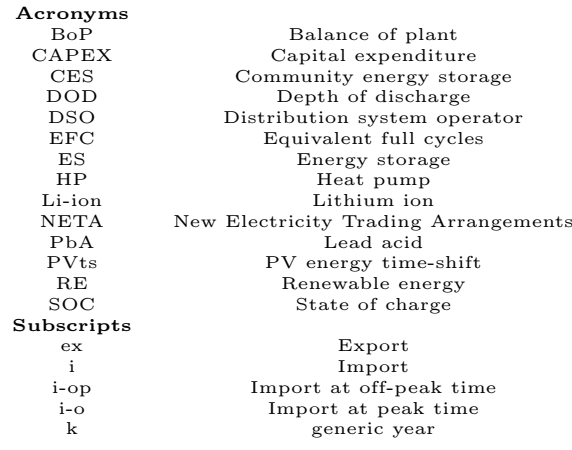

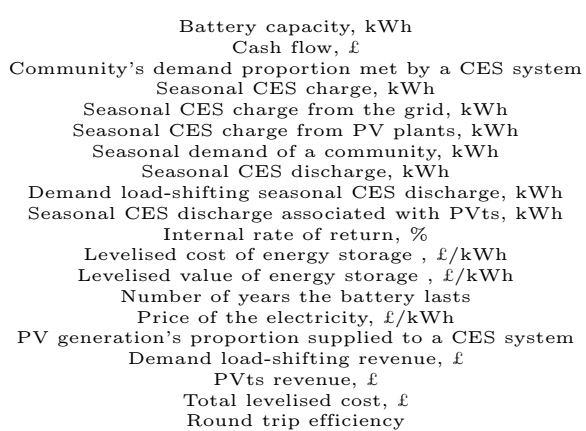




\section{Acknowledgment}

Our acknowledgments to E.ON for supporting this research. The project was also funded by the European Regional Development Fund (grant number EMX06781) by means of the Accelerating Low Carbon Economy Project.

\section{Supplementary information}

\subsection{Battery model}

The $\mathrm{PbA}$ and Li-ion battery performance submodels are based on the equivalent circuit of a battery comprising a voltage source and resistance, the state-ofcharge (SOC) being the main parameter which affects their variations [31, 44]. The lead-acid and lithium-ion battery models were experimentally validated by by J. B. Copetti et al. [45] and by O. Tremblay et al. [46 respectively. A bidirectional inverter is necessary to charge and discharge the battery system during the off-peak and peak period respectively. The rating was optimised following a community approach 28] and was assumed to be equal to half the maximum community peak load. The efficiency of the bidirectional inverter as a function of the load factor was also included in the analysis [47. Companies like Hitachi, Saft and Solom were consulted for the data provided in Table 1 . The minimum discharge time would be 20 min and 2.5 hours for Li-ion and $\mathrm{PbA}$ batteries respectively according to the selected technical characteristics.

The durability submodel is based on the reduction of battery capacity from cycle losses (during charge/discharge) and calendar losses (a time-dependent loss in capacity independent of operation) [48. The battery lifetime was related to the capacity drop to a certain level which was assumed to be $70 \%$ of the initial. The cycle losses were assumed to be linear with the depth of discharge for a given cycle and with the nominal battery capacity, $C_{n o m}(\mathrm{kWh})$, for the SOC ranges indicated in Table 1 using a linear life coefficient characteristic for any battery technology $Z$ according to Eq. 14 47. However, the final cycle life is smaller than the maximum cycle life presented in Table 1 due to the calendar losses. Calendar losses were based on an Arrhenius formula for Li-ion technology [49] and on a linear relationship between the capacity loss and the maximum battery life (years) for PbA technology due to the lack of related data. The key input data for the durability submodels depending on the battery technology are also given in Table 1.

$$
\Delta C=Z \times C_{n o m} \times \Delta S O C
$$

9.2. Algorithms to determine the maximum community energy storage demand

Fig. 11] Fig. 12 and Fig. 13 show a schematic representation of the algorithms utilised to determine the maximum size of a battery system when performing PVts and demand load shifting simultaneously, only demand load shifting and only PVts respectively. 


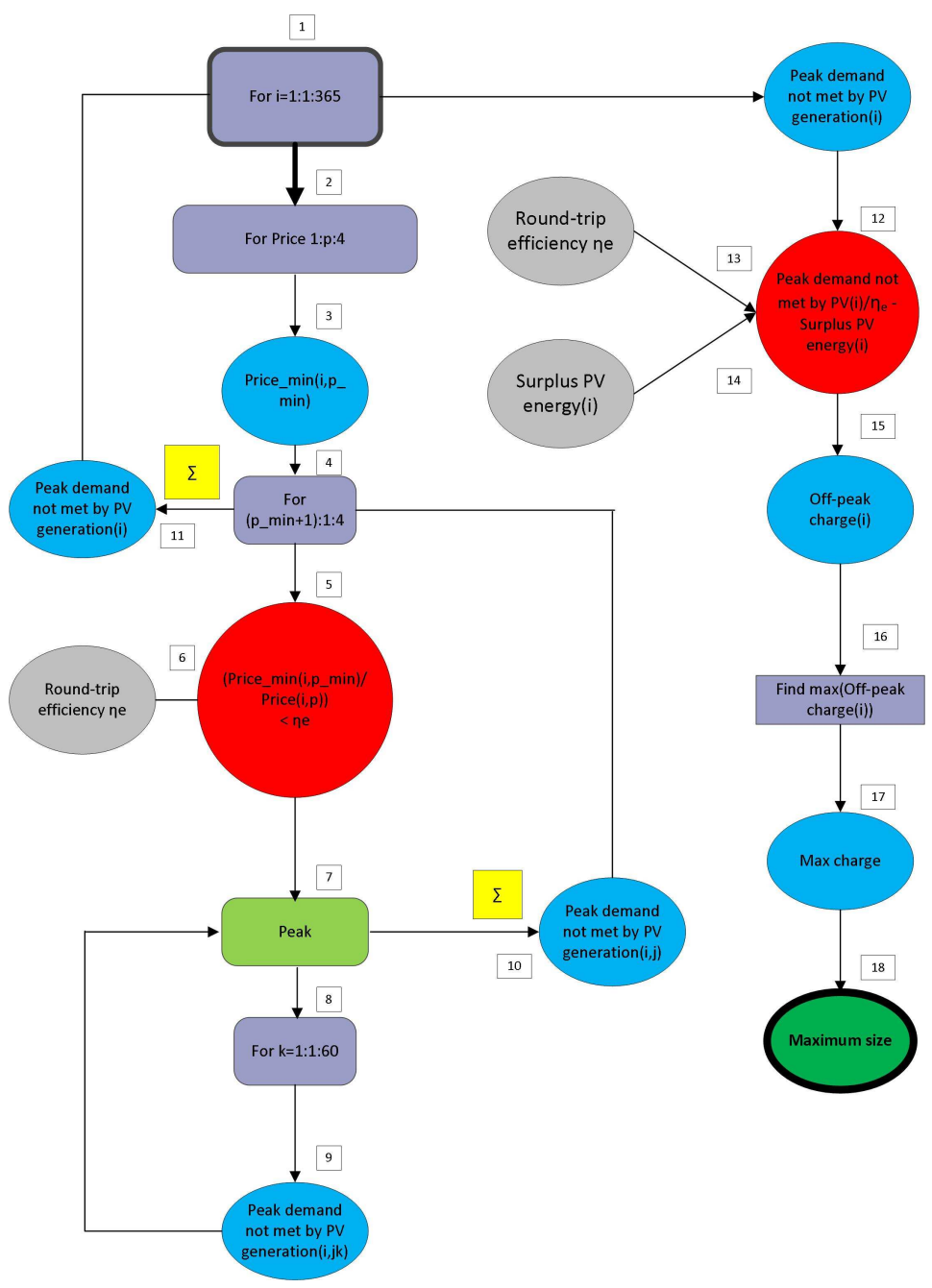

Figure 11: Flow chart representing the algorithm which was utilised to obtain the maximum size of a battery system when performing PVts and demand load-shifting with the NETAbased tariff using 1 minute (loop variable $\mathrm{k}$ ) data for every day (loop variable i) of the year. The flowchart sequence follows the number sequence in the boxes. The sum symbol represents the aggregation of results to obtain hourly values (from 1 minute data) or daily values (from hourly data). The index p represents the four periods of the NETA-based tariff.

\subsection{CES discretisation}

This section shows the different CES systems tested by the optimisation method depending on the application, technology and the reference year. Specifically, the different CES systems were derived from the first step of the optimization method as explained in Section 2.6 


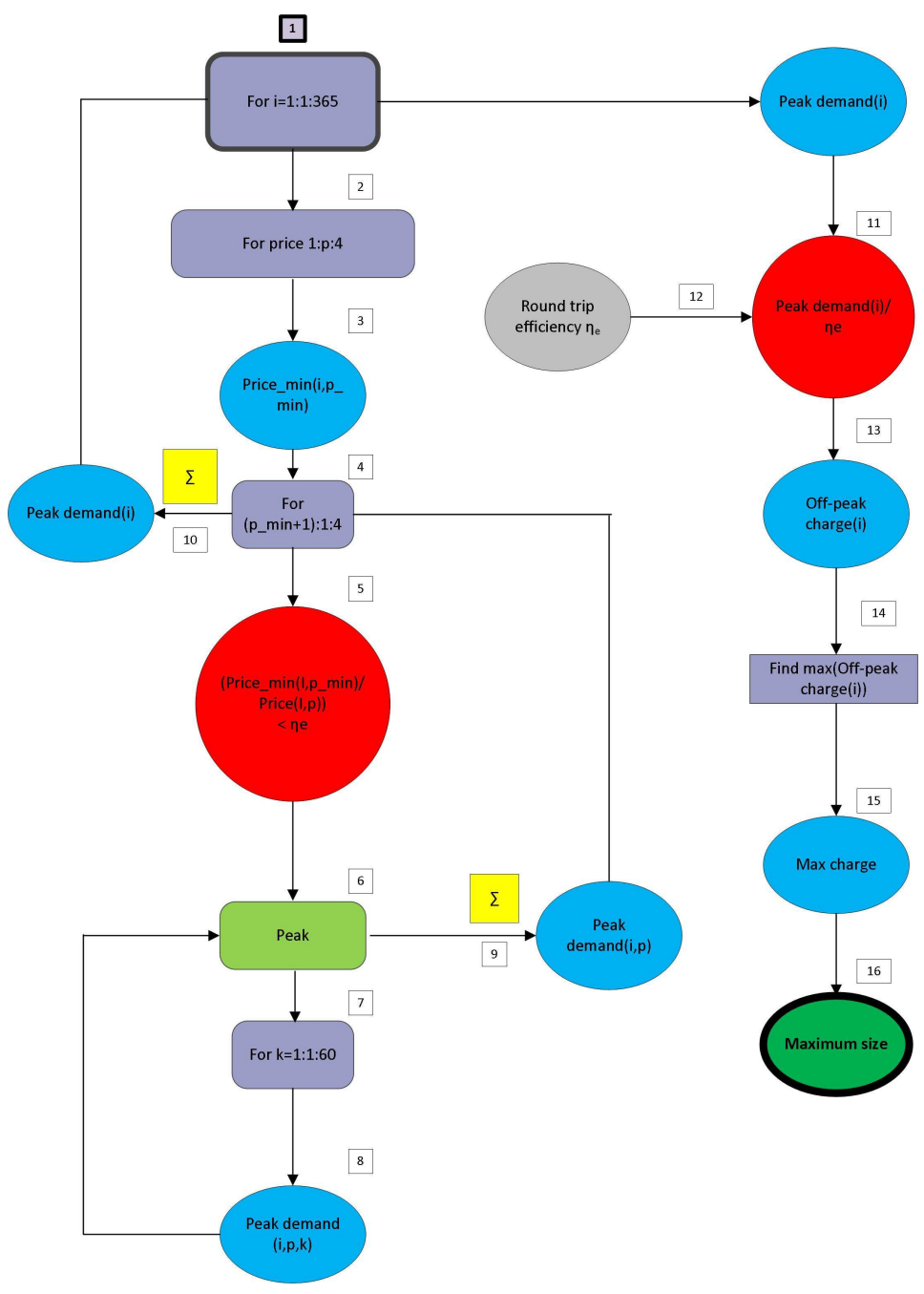

Figure 12: Flow chart representing the algorithm which was utilised to obtain the maximum capacity of a battery system when performing demand load-shifting with the NETA-based tariff using 1 minute (loop variable $\mathrm{k}$ ) data for every day (loop variable i) of the year. The flowchart sequence follows the number sequence in the boxes. The sum symbol represents the aggregation of results to obtain hourly values (from 1 minute data) or daily values (from hourly data). The index p represents the four periods of the NETA-based tariff. 


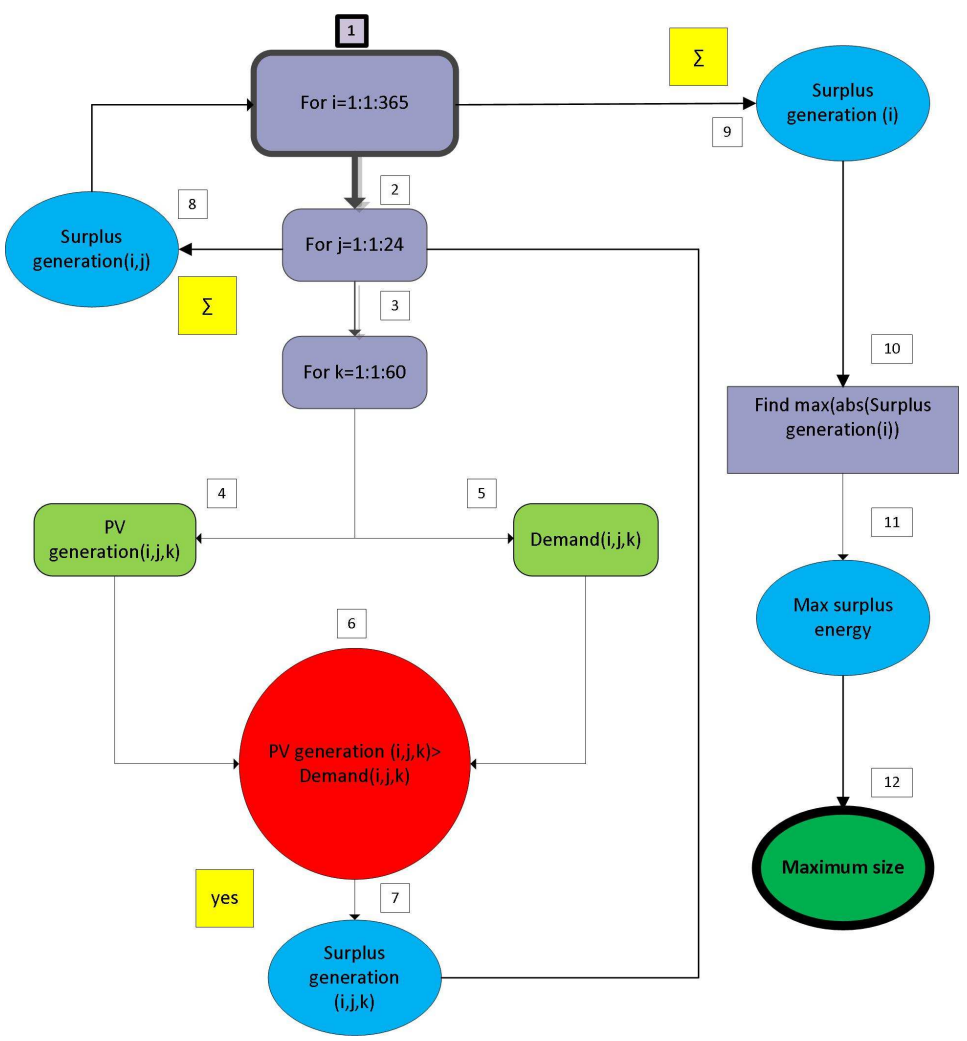

Figure 13: Flow chart representing the algorithm which was utilised to obtain the maximum capacity of a battery system when performing PVts using 1 minute (loop variable $\mathrm{k}$ ) data for every day (loop variable i) of the year. The flowchart sequence follows the number sequence in the boxes. The sum symbol represents the aggregation of results to obtain hourly values (from 1 minute data) or daily values (from hourly data). 

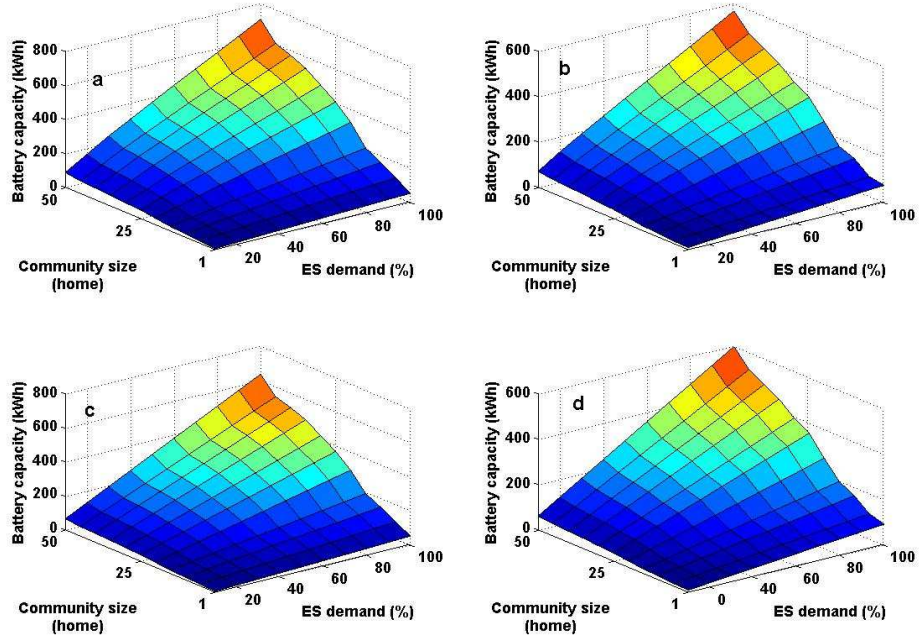

Figure 14: Battery capacity as a percentage of the ES demand for different communities in 2020 for PbA batteries performing (a) PVts and demand load-shifting with the NETAbased tariff and (b) PVts and demand load-shifting with Economy; and for Li-ion batteries performing (c) PVts and demand load-shifting with the NETA-based tariff and (d) PVts and demand load-shifting with Economy. 

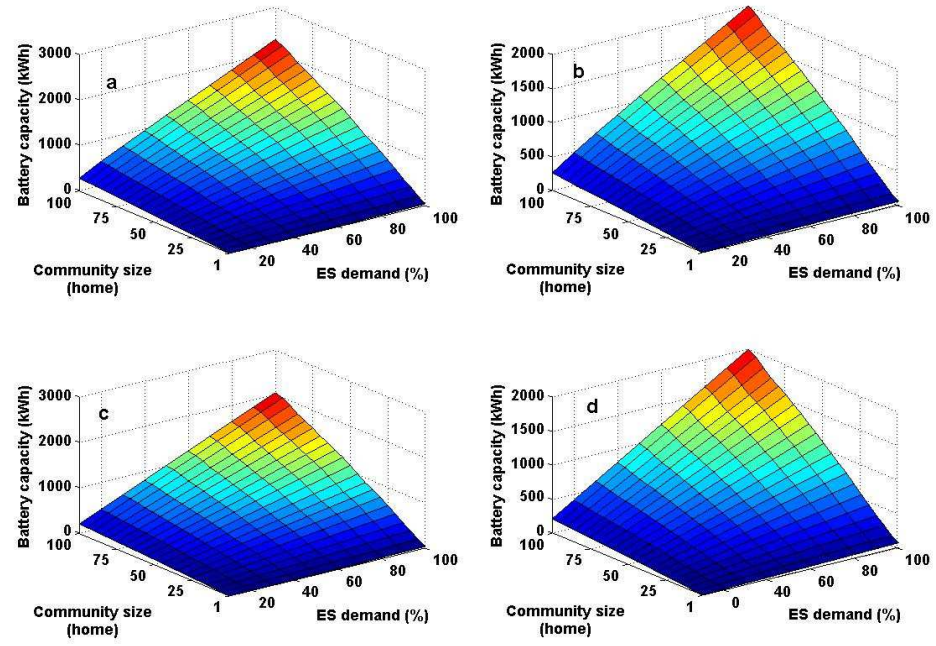

Figure 15: Battery capacity as a percentage of the ES demand for different communities in the zero carbon year for PbA batteries performing (a) PVts and demand load-shifting with the NETA-based tariff and (b) PVts and demand load-shifting with Economy; and for Li-ion batteries performing (c) PVts and demand load-shifting with the NETA-based tariff and (d) PVts and demand load-shifting with Economy. 


\section{References}

[1] J. von Appen, J. H. Braslavsky, J. K. Ward, M. Braun, Sizing and grid impact of pv battery systems-a comparative analysis for australia and germany, in: Smart Electric Distribution Systems and Technologies (EDST), 2015 International Symposium on, IEEE, 2015, pp. 612-619.

[2] R. Kempener, E. Borden, Battery storage for renewables: Market status and technology outlook, Tech. rep., International Renewable Energy Agency, IREMA, (2015).

[3] R. Arghandeh, J. Woyak, A. Onen, J. Jung, R. P. Broadwater, Economic optimal operation of community energy storage systems in competitive energy markets, Applied Energy 135 (2014) 71-80.

[4] A. Nourai, R. Sastry, T. Walker, A vision \& strategy for deployment of energy storage in electric utilities, in: Power and Energy Society General Meeting, 2010 IEEE, IEEE, 2010, pp. 1-4.

[5] Department of Energy and Climate Change, DECC, £5 million boost for energy storage innovation [online], https://www.gov.uk/government/ news/5-million-boost-for-energy-storage-innovation note $=$ Accessed: 2016-06-19 (Sep 2016).

[6] D. Parra, M. Gillott, G. S. Walker, Design, testing and evaluation of a community hydrogen storage system for end user applications, International Journal of Hydrogen Energy 41 (10) (2016) 5215-5229.

[7] Australian Renewable Energy Agency, ARENA, Solar and storage trial at alkimos beach residential development, https://arena.gov.au/project/ solar-and-storage-trial-at-alkimos-beach-residential-development/,note = Accessed: 2016-06-19 (2015).

[8] P. Thomas, T. Walker, C. McCarthy, Demonstration of community energy storage fleet for load leveling, reactive power compensation, and reliability improvement, in: 2012 IEEE Power and Energy Society General Meeting, IEEE, 2012, pp. 1-4.

[9] S. Koopmann, S. Nicolai, A. Schnettler, Multifunctional operation of a virtual power plant in an active distribution grid: Modelling approaches and first field test experiences from the smartregion pellworm project, in: IEEE PES Innovative Smart Grid Technologies, Europe, IEEE, 2014, pp. $1-6$.

[10] B. P. Roberts, C. Sandberg, The role of energy storage in development of smart grids, Proceedings of the IEEE 99 (6) (2011) 1139-1144.

[11] D. Parra, M. Gillott, S. A. Norman, G. S. Walker, Optimum community energy storage system for pv energy time-shift, Applied Energy 137 (2015) $576-587$. 
[12] D. Parra, S. A. Norman, G. S. Walker, M. Gillott, Optimum community energy storage system for demand load shifting, Applied Energy 174 (2016) $130-143$.

[13] S. J. Klein, S. Coffey, Building a sustainable energy future, one community at a time, Renewable and Sustainable Energy Reviews 60 (2016) 867-880.

[14] A. Stephan, B. Battke, M. Beuse, J. Clausdeinken, T. Schmidt, Limiting the public cost of stationary battery deployment by combining applications, Nature Energy 1 (2016) 16079.

[15] Hart, D., Bertuccioli, L., Hansen, X, Policies for storing renewable energy. a scoping study of policy considerations for energy storage (re-storage), Tech. rep., IEA-RETD (2016).

[16] E. Hittinger, J. Whitacre, J. Apt, What properties of grid energy storage are most valuable?, Journal of Power Sources 206 (2012) 436-449.

[17] J. P. Barton, D. G. Infield, Energy storage and its use with intermittent renewable energy, Energy Conversion, IEEE Transactions on 19 (2) (2004) 441-448.

[18] J. M. Santos, P. S. Moura, A. T. d. Almeida, Technical and economic impact of residential electricity storage at local and grid level for portugal, Applied Energy 128 (2014) 254-264.

[19] A. Zucker, T. Hinchliffe, Optimum sizing of pv-attached electricity storage according to power market signals-a case study for germany and italy, Applied Energy 127 (2014) 141-155.

[20] S. Sundararagavan, E. Baker, Evaluating energy storage technologies for wind power integration, Solar Energy 86 (9) (2012) 2707-2717.

[21] N. S. Wade, P. Taylor, P. Lang, P. Jones, Evaluating the benefits of an electrical energy storage system in a future smart grid, Energy Policy 38 (11) (2010) 7180-7188.

[22] J. Sardi, N. Mithulananthan, M. Gallagher, D. Q. Hung, Multiple community energy storage planning in distribution networks using a cost-benefit analysis, Applied Energy 190 (2017) 453-463.

[23] J. Eyer, G. Corey, Energy storage for the electricity grid: Benefits and market potential assessment guide, Sandia National Laboratories Report, SAND2010-0815, Albuquerque, New Mexico.

[24] UK Energy Research Centre, UKERC, Milton keynes energy park dwellings, http://data.ukedc.rl.ac.uk/cgi-bin/dataset_catalogue/ view. cgi. py?id=9, note = Accessed: 2016-06-19 (1990). 
[25] Goverment of the UK, Energy consumption in the uk. domestic data tables. 2011 update, https://www.gov.uk/government/uploads/ system/uploads/attachment_data/file/65954/chapter_3_domestic_ factsheet.pdf|,note $=$ Accessed: 2016-06-19 (Sep 2011).

[26] HM Government, Department of Energy and Climate Change, DECC, 2050 pathways analysis, Tech. rep., HM Government (jul 2010).

[27] A. Moreno-Rodríguez, A. González-Gil, M. Izquierdo, N. Garcia-Hernando, Theoretical model and experimental validation of a direct-expansion solar assisted heat pump for domestic hot water applications, Energy 45 (1) (2012) 704-715.

[28] D. Parra, Optimum community energy storage for end user applications, Ph.D. thesis, University of Nottingham (2014).

URL http://eprints.nottingham.ac.uk/27708/1/David\%20Parra_ Optimum $\% 20$ community $\% 20$ energy $\% 20$ storage $\% 20$ for $\% 20$ end $\% 20$ user $\%$ 20applications.pdf

[29] M. G. Villalva, J. R. Gazoli, et al., Comprehensive approach to modeling and simulation of photovoltaic arrays, Power Electronics, IEEE Transactions on 24 (5) (2009) 1198-1208.

[30] Goverment of the UK, Weekly solar pv installation and capacity based on registration date, https: //www.gov.uk/government/statistical-data-sets/ weekly-solar-pv-installation-and-capacity-based-on-registration-date, note = Accessed: 2016-06-19 (Sep).

[31] D. Parra, G. S. Walker, M. Gillott, Modeling of pv generation, battery and hydrogen storage to investigate the benefits of energy storage for single dwelling, Sustainable Cities and Society 10 (2014) 1-10.

[32] Bolton, Paul, Energy prices standard, http://www.parliament.uk/ briefingpapers/commons/lib/research/briefings/snsg-004153. pdf , note $=$ Accessed: 2016-06-19.

[33] E. S. Trust, Feed-in tariffs scheme (fits) (March 2013). URL http://www.energysavingtrust.org.uk/Generating-energy/ Getting-money-back/Feed-In-Tariffs-scheme-FITs

[34] J. Utley, L. Shorrock, Domestic energy fact file 2008, Department of Energy and Climate Change, BRE, Watford.

[35] D. Feldman, G. Barbose, R. Margolis, R. Wiser, N. Darghouth, A. Goodrich, Photovoltaic (pv) pricing trends: Historical, recent, and near-term projections, Tech. rep., National Renewable Energy Laboratory (NREL), Golden, CO. (2012). 
[36] S. Eckroad, I. Gyuk, Epri-doe handbook of energy storage for transmission \& distribution applications, Electric Power Research Institute, Inc.

[37] E. Consulting, Energy storage. facts and figure. issues, technical solutions and development opportunities, Tech. rep., Enea Consulting (2013).

[38] P. Taylor, R. Bolton, D. Stone, X.-P. Zhang, C. Martin, P. Upham, Pathways for energy storage in the uk, Report for the Centre for Low Carbon Futures, York.

[39] G. Strbac, M. Aunedi, D. Pudjianto, P. Djapic, F. Teng, A. Sturt, D. Jackravut, R. Sansom, V. Yufit, N. Brandon, Strategic assessment of the role and value of energy storage systems in the uk low carbon energy future, Tech. rep., Carbon Trust (2012).

[40] F. J. de Sisternes, J. D. Jenkins, A. Botterud, The value of energy storage in decarbonizing the electricity sector, Applied Energy 175 (2016) 368-379.

[41] International Energy Agency, Technology roadmap. Energy storage, Tech. rep., International Energy Agency (2014).

[42] D. Parra, M. K. Patel, Effect of tariffs on the performance and economic benefits of pv-coupled battery systems, Applied Energy 164 (2016) 175-187.

[43] J. Hoppmann, J. Volland, T. S. Schmidt, V. H. Hoffmann, The economic viability of battery storage for residential solar photovoltaic systems-a review and a simulation model, Renewable and Sustainable Energy Reviews 39 (2014) 1101-1118.

[44] D. Parra, M. Gillott, G. S. Walker, The role of hydrogen in achieving the decarbonization targets for the uk domestic sector, International Journal of Hydrogen Energy 39 (9) (2014) 4158-4169.

[45] J. Copetti, F. Chenlo, Lead/acid batteries for photovoltaic applications. test results and modeling, Journal of power sources 47 (1) (1994) 109-118.

[46] O. Tremblay, L.-A. Dessaint, Experimental validation of a battery dynamic model for ev applications, World Electric Vehicle Journal 3 (2009) 13-16.

[47] Y. Riffonneau, S. Bacha, F. Barruel, S. Ploix, Optimal power flow management for grid connected pv systems with batteries, Sustainable Energy, IEEE Transactions on 2 (3) (2011) 309-320.

[48] Drouilhet, Stephen and Johnson, Bertrand L and others, A battery life prediction method for hybrid power applications, in: AIAA Aerospace Sciences Meeting and Exhibit, 1997.

[49] O. Erdinc, B. Vural, M. Uzunoglu, A dynamic lithium-ion battery model considering the effects of temperature and capacity fading, in: Clean Electrical Power, 2009 International Conference on, IEEE, 2009, pp. 383-386. 